Please send trade news information and illustrations to Kate Craig at the BDJ, 64 Wimpole Street, London WIG 8YS.

For details see the 'How to use' section of the contents page.

\section{Mouth cancer awareness week}

The first ever national Mouth Cancer Awareness Week will take place between 1117 November 2001, aiming to create awareness and better understanding of the disease among the public. The term mouth cancer, rather than oral cancer, will be used to maximise comprehension.

Backed by over 26 professional organisations in medicine, pharmacy and dentistry, (including the BDA, FGDP, GDPA, BDHA, BADN and BDHF) the initiative will attempt to generate high media coverage as a result of a co-ordinated effort. The dental team can play a vital role in increasing public awareness as well as screening for the disease.

There will be a Mouth Cancer Awareness Week stand (H11) at the Dental Showcase exhibition at the NEC from 18-20 October where more information can be obtained.

Any practice wishing to support this initiative can contact Scope Dental Professional Relations on 01722335599 or e-mail pr.scopead@btinternet.com.

Reader response number:
Good practice goes live

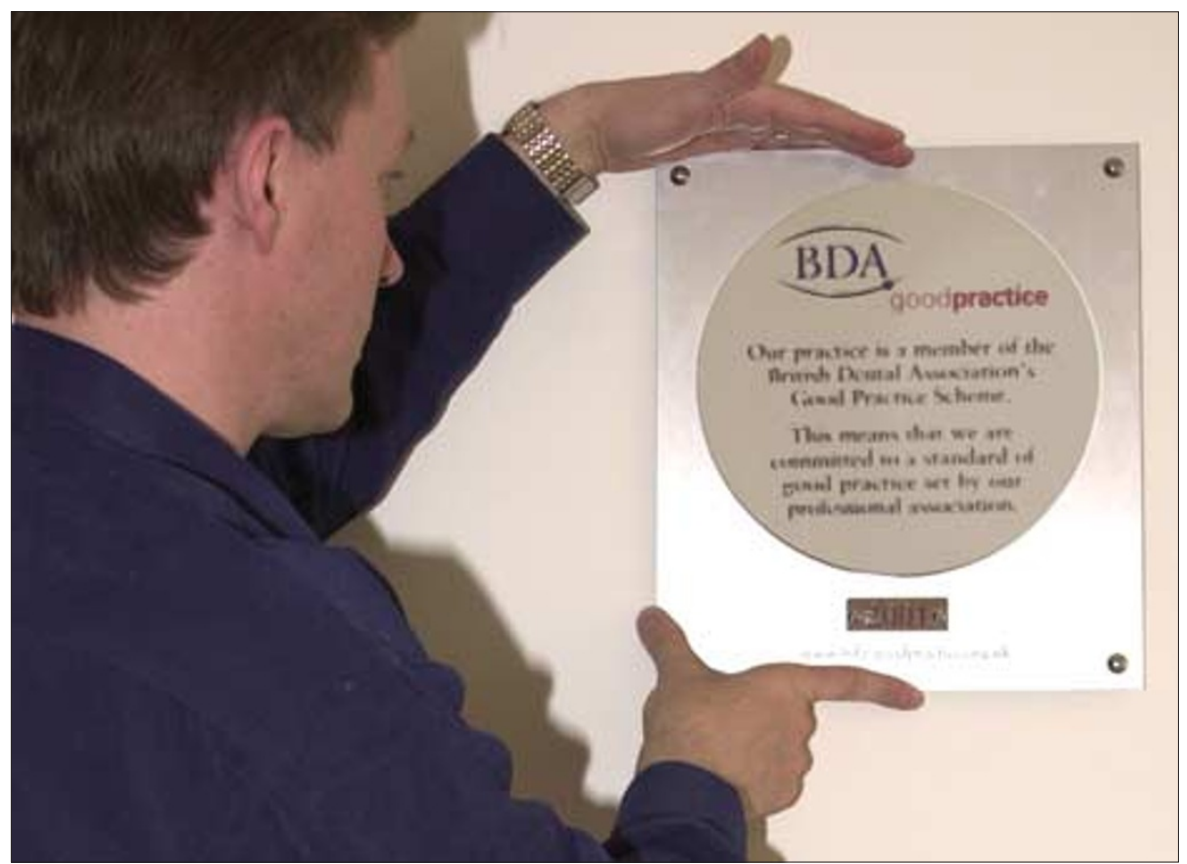

After months of development and fine-tuning, the British Dental Association's Good Practice Scheme goes live at this October's International Dental Showcase in Birmingham.

When the Scheme was first announced in May at the BDA's Annual Conference, the response from the profession exceeded the BDA's expectations. Over the three days in May alone, $\mathrm{X}$ packs were sold to practices wanting to take part in the pre-launch scheme.

Since May, Y practices have completed the necessary audit and the first recipients of BDA Good Practice status will be announced at International Dental Showcase.

The BDA hopes that the Good Practice plaque will become a recognisable brand and will instill confidence in the patients of those practices which have signed up to the Scheme. By working with the Patients' Association in the development of the Scheme, the BDA hopes to have created something which is patient-friendly as well as being useful to practices.

Reader response number:

\section{Dentsply donates to Dentaid}

Dental manufacturer Dentsply recently donated thousands of pounds worth of ultrasonic scaling equipment for use in Third World countries to Landford-based charity, Dentaid.

Dentsply has been collecting used ultrasonic scaling machines and inserts through a trade-in campaign run during 2001 against purchases of Cavitron SPS and Cavitron SPS Jet ultrasonic scalers

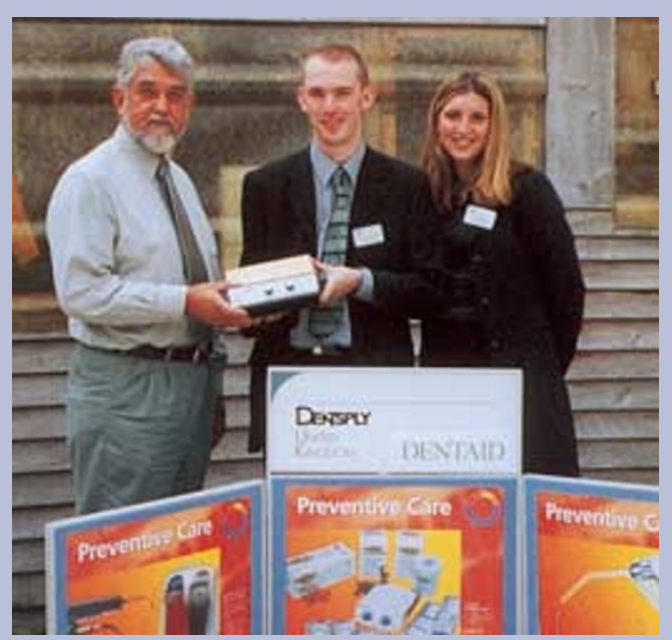
and Cavitron inserts.

Dentaid was established in the UK in 1996 to supply reconditioned dental equipment to the developing world.

During the presentation ceremony, Richard McGowan of Dentsply said, 'Dentsply is very pleased to be ablt to support the vital work that Dentaid conducts. We would like to extend our thanks to the generosity of our customers in donating their old machines when purchasing new Cavitron equipment.

Contact Dentsply on 01932837275.

Reader response number:

\section{LM Instruments EcoExchange 2001}

With the LM EcoExchange it is now possible to replace your old hand instruments with new.

Simply return any 10 old hand instruments in the carton provided, choose any 10 LM Instruments and you will only pay for seven. Return 20 hand instruments and pay for 14, up to 50 instruments may be returned by one customer.

Instruments can be returned to LM Instruments at any of the events listed on the carton or posted directly to LM Instruments. All instruments returned will be donated to the specialist charity Dentaid, who are working to supply refurbished surgeries to rural hospitals in the developing world.

To receive a carton or find out more information about LM Instruments EcoExchange, call 01707-822520 or e-mail jsdsales@js-davis.co.uk.

Reader response number: 


\section{$B D J$ at the forefront of verifiable CPD}

The British Dental Journal has joined forces with Redbus CPD Ltd to make Continuing Professional Development (CPD) easier for busy dental practitioners. Thanks to a new project, organising $\mathrm{CPD}$ could be as simple as putting a CD into your PC.

The new CD-Rom from the $B D J$ and Redbus means that practitioners can take part in verifiable CPD from the comfort of their own home or office, allowing them to work at their own pace. From now on, CPD will be free of the burden of rearranging practice rotas, rescheduling patients' appointments and generally reorganising your life.

Taking centre stage in the first of this ground-breaking series is a seminar on implants sponsored by Astra Tech. Based on Professor Richard Palmer's BDJ book A Clinical Guide to Implants in Dentistry, the seminar, which was filmed earlier this year, involves real participants, and has the added advantage of a question and answer facility.

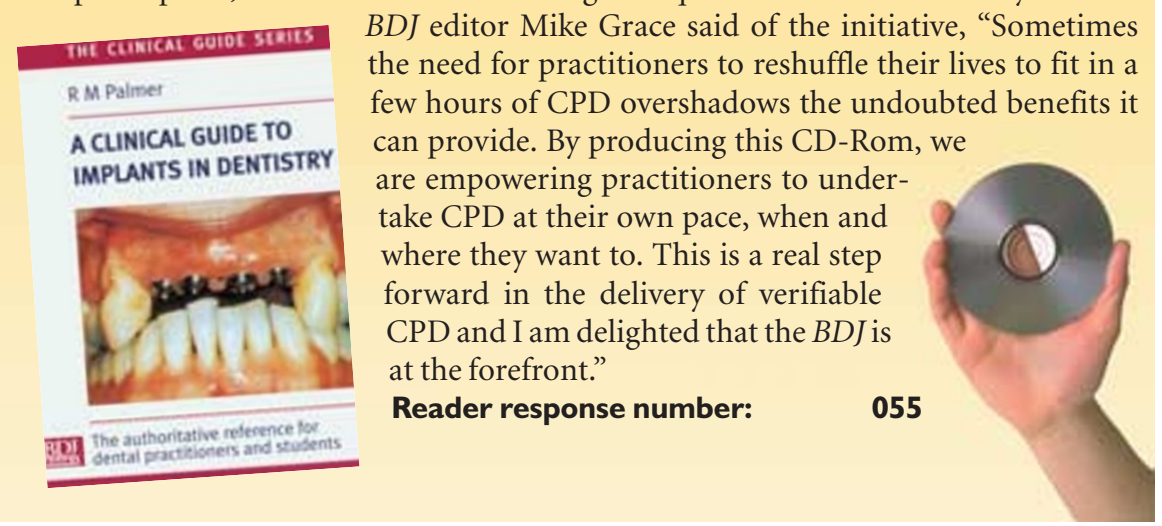

\section{Immediate funding from Bank of Scotland}

Bank of Scotland is launching a new initiative for dentists which aims to help take the pain out of upgrading practices.

At present, dentists throughout Britain are being encouraged to apply for grant aid from the government's $\mathfrak{E} 35$ million Dentistry Modernisation Fund. Under the new scheme, dentists will have to match at least $25 \%$ of their development costs and will not receive any cash from the government until works are complete.

To bridge this funding gap, Bank of Scotland are offering to provide a $100 \%$ advance funding for dentists who qualify for grant aid. Bank of Scotland claims this will enable dentists to refurbish their practices without having to use up their own resources.

'Whilst the grant aid scheme is an excellent initiative which will help dentists enhance their practices, we believe that many may be reluctant to apply because they can't access the funds they need until after work has been taken place,' says Colin Wrigley, Senior Director for Direct Sales with Bank of Scotland.

The Government's scheme was established to ensure that NHS patients receive high quality treatment in modern surroundings. Grant levels are based on the number of surgeries in a practice and the percentage of NHS work carried out with health authorities responsible for notifying each practice of the amount available to them. Phone 0500828111 for details.

Reader response number:

\section{Dürr Dental}

Dürr Dental will be exhibiting several recently launched products including its new range of compressors and the VS600 Suction System at Dental Showcase. Also on the stand will be Vector, the recently launched product for the treatment of periodontal procedures.

Products in the Dürr Dental portfolio include dental air compressors, suction systems, amalgam separators, surgery cleaning and hygiene materials, $\mathrm{x}$-ray processing systems and digital imaging and intra-oral cameras.

Visitors who place an order during the show will be able to buy products at special prices.

To place an order or obtain a copy of DHB Update, DHB's bi-monthly brochure listing special offers, call free-phone 0800 454806 or send an e-mail to sales@dhb.co.uk.

Reader response number:

057 